\title{
Laparoscopic Snaring of Hernia Sac for Inguinal Hernia in Girls: A Preliminary Study
}

\section{Rafik Shalaby ${ }^{\mathbf{1}}$ and Mohamed Ahmed Negm ${ }^{2 *}$}

${ }^{1}$ Department of Pediatric Surgery, Al-Azhar University, Cairo, Egypt

${ }^{2}$ Pediatric Surgery Unit, Qena Faculty of Medicine, South Valley University,

Qena, Egypt

*Corresponding Author: Mohamed Ahmed Negm, M.D, Pediatric Surgery Unit,

Qena Faculty of Medicine, South Valley University, Qena, Egypt.

E-mail: drmohamednegm@yahoo.com

Official E-mail : drmohamednegm@med.svu.edu.eg

ORCID ID: https://orcid.org/0000-0003-0633-9147

DOI: 10.31080/ASPE.2020.03.0210
Received: January 17, 2020;

Published: January 29, 2020

(c) All rights are reserved by Rafik Shalaby and Mohamed Ahmed Negm.

\begin{abstract}
Background: Although open inguinal herniotomy is considered the gold standard for inguinal hernia in all pediatric ages, recently laparoscopic repair with different techniques gained popularity and became widely practiced in many centres worldwide and became one of alternative option for inguinal hernia repair in infant and children. This study reported the initial experience of a novel technique of laparoscopic inversion and snaring of inguinal hernial sac with peritoneal closure of defect at the internal inguinal ring [IIR] in girls.

Methods: Thirty-seven girls with inguinal hernia were subjected to laparoscopic inversion, snaring herniotomy with peritoneal closure at IIR. Follow-up period were more than 10 months.

Results: Thirty-seven girls with 55 hernias were included. Mean age was (39.8 $\pm 18.1 \mathrm{SD}$ ) months. Eighteen (48.64\%) girls presented with right sided, 8 (21.62\%) girls with left sided, and 11 (29.72\%) girls were bilateral CIH Intraoperatively, 7 of U/S diagnosed unilateral cases were found to have a contralateral hernia. In $5(13.5 \%)$ patients associated umbilical hernia were present that repaired in the same sitting. There were no perioperative complications and all cases were completed successfully without conversion. The mean operative time in minutes was $(19.5 \pm 3.1 \mathrm{SD})$ in bilateral while it was $(12.4 \pm 1.6 \mathrm{SD})$ in unilateral cases. Follow up period was ranged from 10 - 33 (Mean $25.02 \pm 6.67 \mathrm{SD}$ ) months with no detected recurrence among the studied patients.

Conclusion: Laparoscopic inversion and snaring of the hernia sac with closure of the peritoneal defect is a safe, rapid and feasible method for inguinal hernia repair in girls without recurrence.

Keywords: Inversion; Hernia sac; Laparoscopy; Girls; Closure of the Peritoneal Defect; Snaring
\end{abstract}

\section{Abbreviations:}

IIR: internal inguinal ring; CIH: congenital inguinal hernia Introduction

For the pediatric surgeon, inguinal hernia repair is the frequently surgical operation in daily practice [1]. Although open surgery is considered the gold standard for all pediatric ages, recently laparoscopic repair gained popularity and became widely practiced in many centres worldwide [2,3] and became one of alternative option of inguinal hernia repair [4].

Laparoscopy for inguinal hernia was firstly done in girls by El Gohary in1997 [5], since then many laparoscopic techniques for inguinal hernia repair was developed aiming for achieving the advantage of minimal invasive surgery and decreasing the rate of recurrence [6-8].

It is well known that, inguinal hernia repair by laparoscopy in girls is a good candidate for improvement and upgrading the learn- ing curve of laparoscopic skills of young surgeon. According to our best knowledge in the English literature there is no reported data about laparoscopic inversion and snaring of inguinal hernial sac at IIR with peritoneal closure of defect in girls. The goal of this study was to present the preliminary experience of this new technique. We refer to this technique as laparoscopic inversion, snaring of hernia sac and peritoneal defect closure in girls.

\section{Patients and Methods}

Over a period of 36 months from the $1^{\text {st }}$ of January 2016 to the $1^{\text {st }}$ of January 2019 a prospective two centres study included 37 girls presented with inguinal hernias. After ethical committee agreement, we included in this study only female children presented by inguinal hernia of one or both sides. Recurrent hernia, complicated cases and cases with internal ring diameter more than $15 \mathrm{~mm}$ measured by preoperative U/S were excluded. Preoperative routine laboratory investigation and inguinal ultrasound to assess the presence of other side and measuring the diameter of both IIR was done. 
All patients were repaired using laparoscopic inversion and snaring of the hernia sac with peritoneal closure.

\section{Operative technique}

Under general anesthesia with Trendelenburg position, initial assessment of both internal rings. The diameter of open internal ring was measured as proposed by Shehata., et al. [9].

Laparoscopic hernia sac inversion was done as described by Lipskar., et al. [10] where hernia sac was completely inverted into the peritoneal cavity. This accomplished through insertion of the ipsilateral Grasper into the hernia sac to grasp its fundus. With freeing any adhesions around the sac, it was twisted on itself 2-3 times. Then the contralateral trocar was removed.

The snare demonstrated in figure 1 was introduced into the abdominal cavity along the $3 \mathrm{~mm}$ grasper from the site of removed trocar. The ipsilateral Grasper was passed into the snare and the hernia sac was re-grasped again and twisted as shown in figure 2 so, the inverted, twisted hernia sac was snared and cauterized slowly with low monopolar cutting diathermy at the neck in interrupted manner.

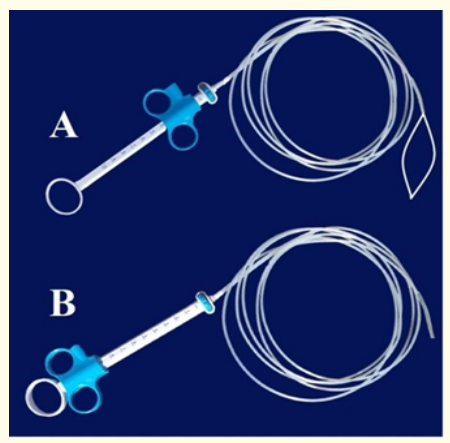

Figure 1: The Snare, [A-Loop of the Snare opened, B-Loop of the Snare closed] "Acusnare polypectomy snare [Cook Medical, Wilson-cook Medical, Inc.4900 Bethania Road Winston-salem NC27105. WWW. Cookmedical. com].

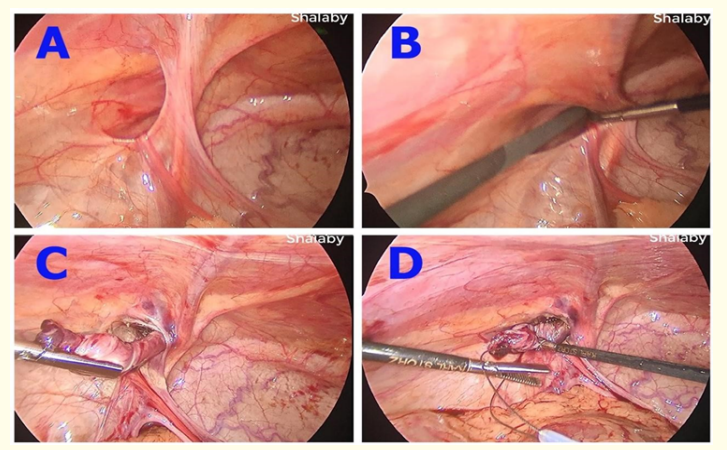

Figure 2: Steps of inversion and insertion of the snare.

A. Left inguinal hernia in a girl.

B. The ipsilateral Grasper is inserted into the hernia sac to grasp its fundus.

C. Inversion and twisting the hernia sac.

D. The Grasper is passing into the opened snare loop.
The twisted snared distal sac was extracted and peritoneal defect was closed with polypropylene suture as shown in figure 3 . In bilateral, cases the same technique was repeated. The umbilical incision was closed after umbilical herniotomy if present. This video link for more details about laparoscopic inversion, snaring and peritoneal closure technique: https://drive.google.com/open ?id=1lU9c8VHH0VQZRxUe1G3W8FmFkYvYGtAf.

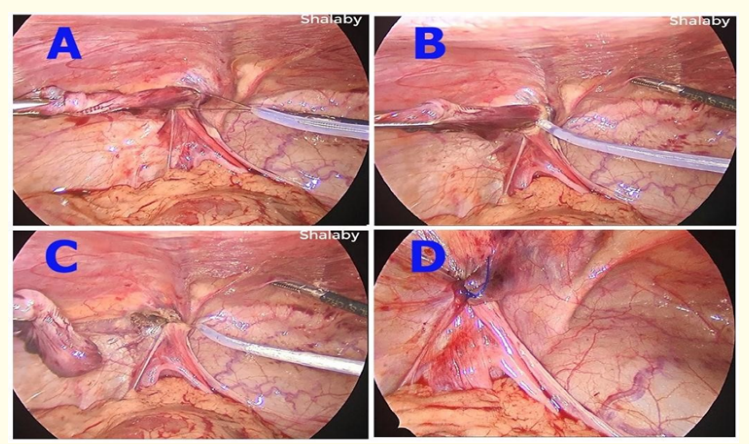

Figure 3: Steps of snaring and suturing of small peritoneal defect.

A. Opened loop of the Snare is encircling the twisted invert ed sac snugly and precisely

B. Closed loop of Snare around the twisted inverted with generation of a low current cutting mode diathermy and proceeding carefully with short buzzes

C. Complete division of the sac with narrow raw area at its neck without much diathermy to the surrounding sutures

D. Closure of the narrow raw area of peritoneal defect

Follow-up was done in out-patient clinic weekly for 2 weeks for the first month, then every 3 months in the first year. All parents were instructed to attend if any abnormality was appeared specially groin swelling.

\section{Results}

This study was carried out on 37 girls with 55 inguinal hernias as shown in figure 4 . Five (13.51\%) patients had associated with umbilical hernia. The patient's age, operative time and follow up period are shown in table 1 . All hernia repaired by laparoscopy using the same technique principles of inversion, snaring of hernia sac with peritoneal closure. No conversions to other laparoscopic techniques or open method were needed in this study. Although the technique was easy and take short time, there were some difficulties in complete inversion the hernia sacs especially in early cases. But after getting familiar with the technique, it became easily done in a shorter time. All patients were discharged from the hospital in the same day. There were no perioperative complications. Associated umbilical hernias were simultaneously repaired in the same setting with no detected complication. The mean follow up was (25.02 $\pm 6.67 \mathrm{SD})$ months with no recurrence detected among the studied patients. 


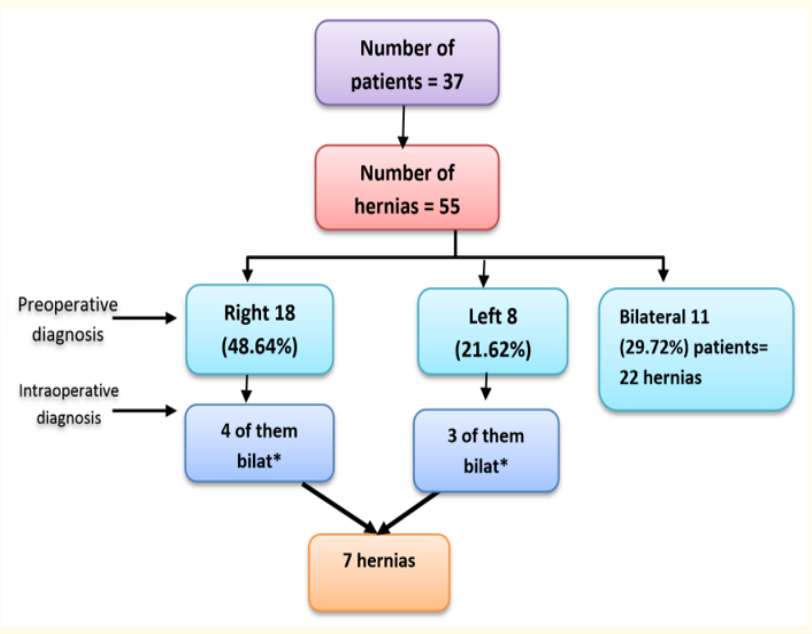

Figure 4: Number of patients and hernias. $\left[{ }^{*}\right.$ These cases were found to be bilateral].

\begin{tabular}{|l|c|c|}
\hline & Range & Mean \\
\hline Age in months & $13-75$ & $39.8 \pm 18.1 \mathrm{SD}$ \\
\hline Operative time in minutes & & \\
Unilateral & $10-15$ & $12.4 \pm 1.6 \mathrm{SD}$ \\
Bilateral & $15-25$ & $19.5 \pm 3.1 \mathrm{SD}$ \\
\hline Follow up in months & $10-33$ & $25.02 \pm 6.67 \mathrm{SD}$ \\
\hline
\end{tabular}

Table 1: Study demographic data.

\section{Discussion}

Over the past years, laparoscopic hernia repair became a wellestablished and popular technique for inguinal hernia in children with good cosmetic outcome in comparison to the standard open technique and the recurrence after surgery. Moreover, laparoscopy allows diagnosis of contralateral hernia can be achieved with simultaneous repair [4,11-13]. The only drawback of this technique is the need of long learning curve compared by conventional open surgery [14].

Laparoscopy for inguinal hernia repair by inversion and ligation using endo loop was first introduced by El Gohary in 1997. This operation initially carried out in females because it is safer than males due to absence of vas and testicular vessels [5].

Another study by Felix Schier in 1998 and included 14 girls repaired by intracorporeal suture for closing the internal ring by two or three $\mathrm{Z}$ suture [15].

Recently, there are many other techniques available for application of laparoscope in inguinal hernia repair especially in girls as inversion ligation, inversion with cauterization and percutaneous ligation [6-8,16-18].
The technique of snaring discussed in this study is used in polypectomy in colonic polyps by the technique of cold or hot snaring with excision of polyps without colonic wall perforation [19].

In the present study, the snare was attached to low current cutting diathermy to decease spread of heat to surrounding structure. We proposed that inversion, encirclement and snaring of the hernia sac results in a herniotomy with narrow raw area at its neck. Moreover, combining herniotomy with peritoneal closure result in sound healing that may prevent or minimize recurrence.

Blatnik., et al. demonstrated experimentally in rabbit models that, intentional peritoneal injury at the site of closure produce durable repair [20] In a study by Novotny., et al. they used the Maryland for inversion and cauterization of the hernia sac in 67 girls with 80 hernias, they added that no recurrence were developed on 25 months follow up only one case complicated by hernia but at the site of side trocar [21] St-Louis., et al. in their study of the effect of thermal injury on the hernia sac using monopolar cautery applied on the anterolateral aspect of the internal ring in 94 female and 178 male children, they reported 3\% recurrence rate. They also concluded that -intentional peritoneal thermal injury was not associated with recurrent rate improvement in their study\|. This may be due to application of thermal cautery of diathermy without excision of hernia sac [22].

In a recent study by Marte., et al. on 28 children of them 12 were girls. They utilized simple internal ring cauterization as done in Burnia technique of Novotny., et al. [21] through transumbilical trocar using a grasper; the sac was inverted and wrapped the grasper in a spaghetti manner. Application of monopolar coagulation diathermy to the grasper itself, the hernia sac will be shrunken with closure of internal ring.

No recurrence was reported with any perioperative complication except for lymphocele developed at the level of labium major in a 6 years girl 2 weeks postoperatively with improvement after 6 months [23].

According to the result of this study, the advantages of inversion, snaring and peritoneal closure technique are short operative time and adequately remove the whole sac in one mass with no remaining peritoneal bridge that may be the cause of recurrence. No recurrence also reported by Zallen and Glick in their study using laparoscopic inversion, twisting and ligation by monofilament absorbable endoloop [6]. Guner., et al. using the same technique with very good result except 2 patients presented by recurrence due to non-excised sac. In the same conversion to open technique was required in another two patients with sliding type hernia [7]. We 
agreed with other authors that girls are good candidate for applying new innovative laparoscopic hernia repair techniques because there is no vas and vessels passing through the IIR. In addition, the majority of young laparoscopic surgeon and resident usually start their training curve with inguinal hernia repair in girls [8].

In this study, this novel technique laparoscopic inversion, snaring of hernia sac and peritoneal closure enables to perform laparoscopic hernia repair in girls easily and efficiently with short time of surgery when compared to others [7]. In the current study, there is no reported recurrence, this may attributed to sac excision together with peritoneal closure by nonabsorbable suture as reported by others [24]. Although this a preliminary study, the results are encouraging to draw a definite conclusion.

\section{Study limitation}

The small number of cases together with inclusion of female children only but, this a preliminary study with further studies specially randomised controlled trials are needed. Another limitation of this study was the price of disposable snare but, its value in decreasing the operative time together with the simplicity of the technique overcome addition of its high price.

\section{Conclusion}

Laparoscopic inversion and snaring of the hernia sac with peritoneal defect closure is reproducible easy and promising method for inguinal hernia repair in girls. It resulted in marked reduction of operative time without recurrence however; further studies and randomised trials are needed.

\section{Source of Funding}

None.

\section{Conflict of Interest}

None.

\section{Bibliography}

1. Lao Oliver B., et al. "Pediatric inguinal hernias, hydroceles, and undescended testicles". Surgical Clinics of North America 92.3 (2012): 487. https://doi.org/10.1016/j.suc.2012.03.017

2. Shalaby Rafik., et al. "Laparoscopic inguinal hernia repair; experience with 874 children". Journal of Pediatric Surgery 49.3 (2014): 460-464. https://doi.org/10.1016/j.jpedsurg.2013.10.019

3. Clarke Simon. "Pediatric inguinal hernia and hydrocele: an evidence-based review in the era of minimal access surgery". Journal of Laparoendoscopic and Advanced Surgical Techniques 20.3 (2010): 305-309. https://doi.org/10.1089/ lap.2010.9997

4. Kantor Navot., et al. "Laparoscopic versus open inguinal hernia repair in children: which is the true gold-standard? A systematic review and meta-analysis". Pediatric Surgery International 35.9 (2019): 1013-1026. https://doi.org/10.1007/ s00383-019-04521-1
5. EL-GOHARY M AMIN. "Laparoscopic ligation of inguinal hernia in girls". Pediatric Endosurgery and Innovative Techniques 1.3 (1997): 185-188. https://doi.org/10.1089/pei.1997.1.185

6. Zallen Garret and Philip L Glick. "Laparoscopic inversion and ligation inguinal hernia repair in girls". Journal of Laparoendoscopic and Advanced Surgical Techniques 17.1 (2007): 143-145. https://doi.org/10.1089/lap.2006.0553

7. Guner Yigit S., et al. "Inversion herniotomy: a laparoscopic technique for female inguinal hernia repair". Journal of Laparoendoscopic and Advanced Surgical Techniques 20.5 (2010): 481-484. https://doi.org/10.1089/lap.2009.0169

8. Xi Hong-Wei, et al. "Transumbilical single-site laparoscopic inguinal hernia inversion and ligation in girls". Journal of Laparoendoscopic and Advanced Surgical Techniques 25.6 (2015): 522-525. https://doi.org/10.1089/lap.2014.0383

9. Shehata Sherif M., et al. "Algorithm of laparoscopic technique in pediatric inguinal hernia: results from experience of 10 years". Journal of Laparoendoscopic and Advanced Surgical Techniques 28.6 (2018): 755-759. https://doi.org/10.1089/ lap.2017.0273

10. Lipskar Aaron M., et al. "Laparoscopic inguinal hernia inversion and ligation in female children: a review of 173 consecutive cases at a single institution". Journal of Paediatric Surgery 45.6 (2010): 1370-1374. https://doi.org/10.1016/j.jpedsurg.2010.02.113

11. Chan Ivy Hau-yee and Paul Kwonghang Tam. "Laparoscopic inguinal hernia repair in infants and children: state-of-theart technique". European Journal of Pediatric Surgery 27.06 (2017): 465-471. https://doi.org/10.1055/s-0037-1608685

12. Jessula Samuel and Dafydd A Davies. "Evidence supporting laparoscopic hernia repair in children". Current Opinion in Pediatrics 30.3 (2018): 405-410. https://doi.org/10.1097/ MOP.0000000000000612

13. Gause Colin D., et al. "Laparoscopic versus open inguinal hernia repair in children $\leq$ : a randomized controlled trial". Pediatric Surgery International (2017): 367-376. https://doi org/10.1007/s00383-016-4029-4

14. Barroso Catarina, et al. "Learning curves for laparoscopic repair of inguinal hernia and communicating hydrocele in children". Frontiers in Pediatrics 5 (2017): 207. https://doi. org/10.3389/fped.2017.00207

15. Schier F. "Laparoscopic herniorrhaphy in girls". Journal of paediatric surgery 33.10 (1998): 1495-1497. https://doi org/10.1016/S0022-3468(98)90483-3 
16. Ostlie Daniel J and Todd A Ponsky. "Technical options of the laparoscopic pediatric inguinal hernia repair". Journal of Laparoendoscopic and Advanced Surgical Techniques 24.3 (2014): 194-198. https://doi.org/10.1089/lap.2014.0081

17. Shalaby Rafik., et al. "Laparoscopic hernia repair in infancy and childhood: evaluation of 2 different techniques". Journal of Pediatric Surgery 45.11 (2010): 2210-2216. https://doi. org/10.1016/j.jpedsurg.2010.07.004

18. Shalaby Rafik., et al. "Novel application of the sewing machine principle; a new simplified intracorporeal suturing technique for pediatric inguinal hernia". Journal of Pediatric Surgery (2019). https://doi.org/10.1016/j.jpedsurg.2019.01.054

19. Chen Yen-Nien., et al. "Comparison of cold and hot snaring polypectomy for small colorectal polyps: study protocol for a randomized controlled trial". Trials 19.1 (2018): 361. https:// doi.org/10.1186/s13063-018-2743-z

20. Blatnik Jeffrey A., et al. "Stitch versus scar-Evaluation of laparoscopic pediatric inguinal hernia repair: A pilot study in a rabbit model". Journal of Laparoendoscopic and Advanced Surgical Techniques 22.8 (2012): 848-851. https://doi.org/10.1089/ lap.2012.0137

21. Novotny Nathan M., et al. "The Burnia: laparoscopic sutureless inguinal hernia repair in girls". Journal of Laparoendoscopic and Advanced Surgical Techniques 27.4 (2017): 430-433. https://doi.org/10.1089/lap.2016.0234

22. St-Louis Etienne., et al. "Experience with peritoneal thermal injury during subcutaneous endoscopically assisted ligation for pediatric inguinal hernia". Journal of Pediatric Surgery 53.5 (2018): 968-972. https://doi.org/10.1016/j.jpedsurg.2018.02.024

23. Marte Antonio., et al. "Toward sutureless laparoscopic inguinal repair in children?". La Pediatria medica e chirurgica: Medical and Surgical Pediatrics 41.1 (2019): 167. PMID:30896137 DOI: $10.4081 /$ pmc.2019.167

24. Grimsby GM., et al. "Non-absorbable sutures are associated with lower recurrence rates in laparoscopic percutaneous inguinal hernia ligation". Journal of Pediatric Urology 11.5 (2015): 275-e1. https://doi.org/10.1016/j.jpurol.2015.04.029

\section{Assets from publication with us}

- Prompt Acknowledgement after receiving the article

- Thorough Double blinded peer review

- Rapid Publication

- Issue of Publication Certificate

- High visibility of your Published work

Website: www.actascientific.com/

Submit Article: www.actascientific.com/submission.php Email us: editor@actascientific.com

Contact us: +919182824667 